\title{
Blandine Chelini-Pont, Raphaël Liogier, dirs., Géopolitique du christianisme.
}

Ellipses, Référence Géopolitique, 2003, 189 p.

Camille Tarot

\section{OpenEdition}

Édition électronique

URL : http://journals.openedition.org/assr/3103

DOI : 10.4000/assr.3103

ISSN : $1777-5825$

Éditeur

Éditions de l'EHESS

Édition imprimée

Date de publication : 1 décembre 2005

Pagination : 215-311

ISBN : 2-7132-2045-9

ISSN : 0335-5985

\section{Référence électronique}

Camille Tarot, « Blandine Chelini-Pont, Raphaël Liogier, dirs., Géopolitique du christianisme. », Archives de sciences sociales des religions [En ligne], 131-132 | juillet - décembre 2005, document 132-8, mis en ligne le 20 février 2006, consulté le 21 septembre 2020. URL : http://journals.openedition.org/assr/ 3103 ; DOI : https://doi.org/10.4000/assr.3103

Ce document a été généré automatiquement le 21 septembre 2020

(C) Archives de sciences sociales des religions 


\title{
Blandine Chelini-Pont, Raphaël Liogier, dirs., Géopolitique du christianisme.
}

Ellipses, Référence Géopolitique, 2003, 189 p.

\author{
Camille Tarot
}

1 Si au sens restreint, la géopolitique se définit par l'étude des rapports (de contrainte, de dépendance, d'intérêt, d'instrumentalisation, etc.) qui lient toute politique à un espace, au sens large, elle poursuit ce dessein en privilégiant le niveau des relations internationales et des équilibres mondiaux. Une première conviction de cet ouvrage collectif est que l'option géopolitique, en ce dernier sens, doit intégrer la religion comme « une donnée majeure de toute culture géographiquement située, précédent en importance les intérêts stratégiques et économiques » (Chelini-Pont, 19). La deuxième est que le christianisme est actuellement «en travail dans la mondialisation ». Et qu'enfin, cette mondialisation lui offre des chances et des possibilités qu'il s'agit aussi de mesurer : «Cet ouvrage compte faire le point sur les ressources spécifiques dont dispose le christianisme dans ses diversités originelles, susceptibles d'être mobilisées efficacement dans le cadre d'une société mondiale en phase de transnationalisation » (Chelini-Pont, 20).

2 Dans ce cadre général, l'approche est double. D'abord, par grande famille chrétienne. Ainsi, avec l'effondrement du communisme, l'orthodoxie (François Thual) se trouve propulsée dans une donne géopolitique très nouvelle, mais pas plus facile pour autant, par exemple dans les Balkans, en Russie ou en Ukraine. Le catholicisme, un peu trop vu sous le seul angle de la diplomatie vaticane (Gérard Frémiot) apparaît, sans surprise, comme un vieux roulier de la géopolitique, tandis que le protestantisme (Sébatien Fath), grâce en particulier à l'actuelle prééminence des États-Unis et aux succès foudroyants du pentecôtisme, se voit propulsé sur le devant de la scène mondiale chrétienne.

3 L'autre approche jauge l'impact, les chances et les limites du christianisme, continent par continent, tant les situations sont différentes, en effet, entre des Amériques 
massivement chrétiennes et l'Asie au christianisme infinitésimal. Jean Gueit souligne le rôle décisif de l'œcuménisme chrétien, nécessaire mais fragile, dans la construction européenne. Régis Ladous traite fort bien des effets du pluralisme religieux sur les christianismes états-uniens, mais aussi sur la politique américaine, ses débats sur la laïcité ou les blocages du melting pot. Tout autre, évidemment, est l'impact géopolitique des Églises d'Asie (Jacques Gadille) ou des vieilles Églises proches orientales (Samir Khalil Samir) dont la situation dans l'océan islamique est si complexe et, présentement, particulièrement tendue.

4 Quelques idées communes ou pressentiments d'avenir se dégagent de ces diverses approches. D'abord que le christianisme est un acteur majeur de la mondialisation, ensuite qu'il lui est particulièrement bien adapté, de part ses principes congénitaux d'universalité et d'historicité, par sa capacité à s'inculturer à des mondes multiples et à rebondir face aux défis historiques. Il ressort surtout, que la mondialisation impose aussi aux vieilles confessions chrétiennes ses logiques neuves et pourrait les pousser à générer des figures nouvelles de l'être chrétien. De ce point de vue le pentecôtisme, assurément protestant et modernisateur, refond bien d'autres héritages (Walter J. Hollenweger) en une combinaison novatrice, mais non sans faiblesses, en particulier intellectuelles. Néanmoins, il pourrait être fort symptomatique d'un christianisme mondialisé encore ou proche à venir.

5 Cet ouvrage intéressera le sociologue à plus d'un titre. Par rapport aux études de sociologie religieuse classiques, où prévalent microsociologie et européocentrisme sans soupçon, il opère un élargissement et un déplacement du regard, qui veulent révéler une dynamique chrétienne à laquelle l'Europe n'est plus guère habituée. En montrant " une recomposition chrétienne en phase avec la recomposition sociopolitique du monde » (20), il interpelle la sociologie qui s'est plus habituée « au moins en Europe, (à) un retrait intérieur du christianisme par rapport à sa prétention universelle originelle.. » (Pena, p. 28).

6 Mais d'autre part, l'ouvrage n'hésite pas à passer sinon à la contre-offensive critique, du moins à la prospective, lorsque, par exemple, sous la plume de Raphaël Liogier, il se demande si la recombinaison mondiale du christianisme avec les Droits de l'homme ne serait pas la réponse d'une nouvelle légitimité chrétienne capable, face à ce qu'il appelle le «schizo-humanisme» qui minerait l'actuelle modernité, de dépasser les impasses d'une civilisation sans religion. Le sociologue pourra craindre qu'on ait franchi la séparation du positif et du normatif ou du réel et du possible ou du souhaitable, à moins qu'il n'y voit, justement, l'indice d'une recomposition qui interpellerait même l'épistémologie de sa science et qu'il estime alors ne pas devoir laisser seuls le philosophe et éventuellement le théologien prendre part au débat avec la géopolitique. 